\title{
Las tendencias globalizadoras: dos mundos*
}

$\underline{Q}$ 1 mundo de hoy, el único mundo en el que puede vivir la Humanidad, es escenario de grandes transformaciones en todos los órdenes. Cambios cuya dimensión e intensidad además de no tener precedentes en la historia alcanzan inexorablemente una escala planetaria. Por ello, debemos conocer "las tendencias globalizadoras" y preguntamos como nos afectan y que papel podemos jugar como país y como individuos frente a esas fuerzas centrífugas de cambio.

El primer gran hecho histórico irrebatible es el inquietante crecimiento demográfico. En 1990 la población mundial sobrepasó los 5,000 millones de habitantes, cifra que se incrementa en 1,000 millones cada década. El problema radica en la tasa de crecimiento; desde hace 200,000 años hasta el descubrimiento de América la población mundial era del orden de los 500 millones, en tan solo 2 siglos después duplicamos la cifra y en un sólo siglo más volvimos a duplicar la población (Gore: 1993, 41). Si desde los albores de la humanidad hasta mediados del presente siglo, sucedieron 10,000 generaciones las necesarias para llegar a 2,000 millones de habitantes; ahora, basta una generación para duplicar la población. Este crecimiento geométrico de la población, imemisiblemente plantea una mayor presión sobre los recursos naturales necesarios para la reproducción de la especie humana.

Conviene resaltar que la explosión demográfica no es de ningún modo simétrica, los llamados países desarrollados han pasado a un crecimiento estable, de sustitución, mientras los países de menor desarrollo están abatidos por un incontrolable crecimiento demográfico. Donde hay menos tecnología hay mayores

- Este artículo fue presentado en el Seminario sobre Derechos Humanos Económicos, Sociales y Culturales en la Procuraduría de Derechos Humanos, el 4 de junio de 1996. 
presiones por los espacios y recursos y viceversa. La relación hombre naturaleza de permanente equilibrio tiende a quebrarse. En una gran parte del mundo la urbanización, las crecientes necesidades por los espacios, las exigencias por mayores disponibilidades de recursos ejercen gran presión sobre el equilibrio. Una vez roto ese equilibrio, podrían exacerbarse nuevas tensiones sociales a niveles incluso planetarios.

Si en el siglo XVIII se resolvió con relativa facilidad la explosión demográfica, mediante la revolución agrícola, la revolución industrial y las crecientes migraciones de Europa hacia el nuevo continente, Africa y Australia, ahora los amenazantes flujos migratorios del tercer mundo hacia el primer mundo, tropiezan con las severas medidas antiinmigratorias aunado con la xenofobia.

El desequilibrio demográfico mundial no es más una amenaza contra el respeto a los derechos humanos más elementales, es una realidad. El 80 por ciento de la población mundial, por medio de sus televisores, presencia casi simultáneamente las agresiones físicas contra los inmigrantes ilegales. Las hambrunas, pestes y mal nutrición de grandes regiones del mundo contrastan con el reino de jauja que promete el desarrollo tecnológico. El desequilibrio demográfico mundial evidencia sin más, la existencia de dos mundos diametrialmente opuestos.

El afán por dominar el mundo, la búsqueda incesante por el beneficio, la necesidad incontrolable por rendir tributo a la productividad —entre otroscondiciona y presiona por un segundo hecho relevante: el cambio tecnológico. Basta con hablar de tecnologías de punta como la cibemética, informática, biolecnología, aeronáutica, robótica, etc., para compartir las ilusiones de que con ellas se salvará la humanidad y que la profecía sobre el holocausto de la vieja Inglaterra de Malthus no tiene cabida en la historia.

No obstante, el desanollo tecnológico actual vuelve a dividir al mundo en dos: una gigantesca brecha tecnológica. Si bien, con ella tiende a vencerse con creces la productividad, la brecha tecnológica amenaza con volver obsoletas la producción agrícola del tercer mundo. Entonces, paradójicamente, debería cobrar relevancia desde esa perspectiva, la defensa de los derechos humanos individuales porque se amenaza la vida misma y la discusión sobre los derechos humanos económicos, sociales y culturales, alcanza un nivel más lejano, por lo menos para la gran parte del mundo cuyo rezago los ubica en la era de la revolución agrícola de hace 200 años.

Con el avance tecnológico destaca otro hecho trascendente que es necesario dilucidar: la cultura que generan los medios de comunicación masiva, especialmente la televisión.

Existen 120 satélites en nuestro espacio conectando virtualmente a todo el mundo - aunque la TV tenga apenas $40 \circ 50$ años desde su aparecimiento, en la actualidad hay mil doscientos millones de televisores en el mundo. (UNRISD, 
1995: 9-10). Con ese solo medio se tiene un nuevo miembro en la familia. Tenemos que compartir con él la educación de nuestros hijos. Una tarea tradicionalmente confiada a los padres es ahora labor de un extraño. A partir de allí se va configurando como formador y no sólo informador. Un mecanismo elegante y subliminal que dicta y confiere nuevos patrones. Tanto ha penetrado en el fuero interno de nuestro hogares que se convierte en el primer referente para la toma de decisiones, particularmente las relacionadas al consumo. Es un elemento que nutre ilusiones y que vende todos los dias y a toda hora. Este fenómeno tiene una trascendencia incalculable sobre la humanidad que nuevamente divide al mundo en dos: el real y el imaginario.

También es impresionante el rol que puedan desempeñar otras formas de comunicación como el Intemet, la telefonía y el transporte, los cuales conectan al mundo como nunca antes.

La interconexión de los avances tecnológicos sobre lodo los que impulsan las comunicaciones han servido de excelente insumo para potenciar un cuarto elemento: la vertiginosidad de las transacciones financieras. "Un sólo edificio de New York aloja un sistema de computación que todos los días transfiere un billón de dólares. El equivalente a la emisión monetaria de los Estados Unidos" (UNRISD, 1995: 8). Diversos países del mundos se conectan diariamente con extraordinaria facilidad. Este fenómenos ha sido dinamizado tras la relativa liberalización del comercio mundial y la caída de la mayoría de las barreras arancelarias.

Nuevamente, este hecho divide a el mundo en dos: los que participan y los que, por diversas razones, están excluidos.

Los últimos hechos se entretejen para hilvanar un quinto hecho: la transformación de los sistemas de producción y de los mercados de trabajo. Se ha pasado de la producción a gran escala (modelo fordista y taylorista) a la producción de reemplazo, dinámica, pequeña y flexible. Tal transformación se fundamenta en la adopción de alta tecnología lo cual a su vez supone un mayor grado de capacitación. El resultado neto es el aparecimiento de bienes más baratos que pocos pueden comprar, la subcontratación como mecanismo que exonera a las grandes empresas al pago de prestaciones y la expulsión de mano de obra poco calificada.

Un quinto fenómeno es el predominio de la liberalización económica aparejada al disminuido papel del esiado en asuntos económicos, como mecanismo para acceder al desarrollo.

La discusión central se ubica en términos de que el mercado es más eficaz para garantizar la estabilidad y el crecimiento sostenido, mientras prevalece el concenso, a menudo más ideológico que real, de achacar al estado la culpa de los grandes males económicos (Fislow, 2). 
Sin pretender resolver el debate, llama la atención la evidencia de que habiéndose adherido grandes partes del mundo al mercado, no han experimentado los mágicos resultados esperados.

La anticipada victoria del laisse-faire como única forma para acceder al desarrollo ha sido reforzada por la caída del bloque socialista. La finalización de la guerra fría trae acompañada la pérdida de referentes políticos para los movimientos populares secularmente excluidos del progreso económico y social.

Como mecanismo de acceso al poder parece estar legitimada la vía de las elecciones. Los regímenes así elegidos constituyen democracias formales cuyos esfuerzos por remover las raíces de los problemas que sumen a gran parte del mundo en el retraso, son casi nulos. La conquista de la democracia real, que encama la voluntad individual de elección política y fundamentalmente el acceso al bienestar económico y social, parece ser una discusión soslayada. Entre tanto los conflictos territoriales, étnicos, económicos y políticos solo han sido diferidos, no resueltos.

El último hecho -a mi entender- de magnitud planetaria es el deterioro ecológico: el calentamiento, el agujero de ozono, la contaminación, la desaparición de especies, etcétera.

El fenómeno ha merecido incluso la realización de una cumbre mundial de mandatarios. Más allá de dilucidar el problema fuera de las fronteras, baste decir que este es el segundo país del continente más deteriorado ecológicamente. Por lo tanto, no debemos diferir las soluciones por más tiempo.

Las anteriores tendencias globalizadoras no son en ningún modo demarcables con facilidad. Se ciemen como un entramado de relaciones de gran complejidad cuyos impactos todavía no son claramente previsibles. Sin embargo, resulta logica la presunción de que el mundo globalizado tiene caraclerísticas duales. Es decir, aparece una paradoja: en un planeta de relaciones en todos los ordenes mundializadas, hay una fuerza dominante (el laisses fair) poderosa y arrasante que divide y arroja dos productos. La minoría desarrollada y triunfante y la mayoría subdesarrollada y derrotada.

\section{El rompimiento de inercias.}

Frente a esas transformaciones inexorables, la pregunta que surge es: qué tan preparado está el tercer mundo y este país para afrontar los desafios del cambio?

La postura más obvia es la pesimista. Es decir, no estamos preparados para responder en condiciones de abismal desigualdad e introducimos consciente o inconscientemente al imperio del caos como lo diŕa Samir Amín o a los Estados de desorden del Instituto Interamericano de Derechos Humanos. Entonces, sometámonos sin más a la inercia transformadora. 
La postura difícil es la optimista, porque no está clara y porque exige cambios, desde las actitudes individuales hasta las visiones sostenibles para el largo plazo que hemos de heredar.

Si bien es cierto que los cambios son inminentes y que lo querramos o no van a afectamos, la primera cuestión que debemos resolver es la de la interpretación correcta de los hechos. Es bien sabido que los economistas y la mayoría de cientistas sociales, son colocados por los medios de comunicación en una suerte de diálogo bipolar en donde sobresalen los desacuerdos, las soluciones opuestas a los mismos problemas. Sin embargo, no es el acuerdo universal lo que caracteriza a la ciencia sino la voluntad de considerar la evidencia (Hirshleifer, 1992: 4). Aquellos comprometidos con el bien y con la verdad, a menudo serán impopulares porque tendrán la posibilidad de advertir sobre las consecuencias de la toma de decisiones. A pesar de ello, esa larea es ineludible puesto que dará oportunidad para cometer menos errores.

La actitud que interesa destacar es que el afán por sobresaltar los desacuerdos, es entendible para la opinión común, pero entre profesionales, entre personas comprometidas con la necesidad del cambio, son inadmisibles las posturass retóricas e ideológizadas. Es decir, para la transformación positiva no solo hace falta estar concientes sobre la existencia de flagrantes desigualdades, eso es necesario pero lo que hace falta es la propuesta realista y técnica.

La posibilidad de deducir responsabilidades deriva no de la declaración de buenas intenciones sino de la capacidad de anticipar las consecuencias. Pues bien conocidos los problemas, dimensionados y sus causas hace falta proseguir con el compromiso ineludible de romper las inercias. Este sencillo asunto pasa por vencer en primer lugar nuestra propia inercia de resistir el cambio. En segundo lugar hace falta tomar a cuestas la transformación honda de nuestra realidad y encauzarla tras una ruta delineada a lo positivo desde la perspectiva en la que estamos capacitado para hacerlo y desde la convicción de que no es excluyendo a las mayorías como se alcanzará el desarrollo. En tercer lugar es imperalivo asumir la responsabilidad individual y ponemos a trabajar, quizá no para nosotros mismos sino para las generaciones venideras.

En este mundo dual en donde el corto plazo es el interés de los políticos el cortísimo plazo, el interés de las mayorías empobrecidas lo abstracto, el interés de los académicos, la vertiginosidad, el afán tecnológico, los intereses creados, el móvil de las minorías, hace falta contraponer un compromiso reflexionado, filosofado, historizado, y operativizado ahora para legarlo con orgullo. La urgencia por el acortamiento de las brechas exige multiplicar e integrar esfuerzos bajo un sólo propósito: superar el rezago.

No es el sólo trabajo el que va a proporcionar el acercamiento hacia modelos exitosos, eso es tan cierto como el mínimo acuerdo por la necesidad del crecimiento y la estabilidad macroeconómica como condiciones para la reaclivación 
(condiciones de partida sumamente diff́ciles de alcanzar y sostener), hace falta también que el consenso sobre las bondades de la educación para propiciar el desarrollo integren otros ámbitos bajo una nueva ética de responsabilidades globales. Es decir, se requiere el respeto a la naturaleza, a los valores cívicos, a la democracia, a la consideración del papel de la mujer como elemento básico dentro de esa transformación.

La inercia más grande a romper, a parte de volver a la ética del trabajo es la consideración de que el rompimiento de los sistemas equilibrados terminan con desgarrar todo lo que hay tras su paso. No es posible infringir las leyes de la naturaleza creyendo que sus efectos solo impactaran a los más débiles.

No quisiera dejar la sensación apocalíptica del fin de la historia, sino la consideración de que la humanidad tendrá la capacidad de revertir las tendencias destructoras y adecuarse sin prepotencias a las nuevas exigencias.

\section{Conclusión}

La conversión del mundo nos arroja una explosión demográfica en una parte del globo y una explosión tecnológica en otra, lo cual no es una buena receta para un orden internacional estable (Kennedy: 427). Por su parte la explosión demográfica y el consumismo descontrolado conduce a una incontrolada explotación de los recursos, lo cual provoca su consecuente deterioro.

Parece ser que no nos encontramos frente a un nuevo orden internacional sino frente a un mundo fracturado y desordenado, un escenario de dos mundos conectados, interdependientes, y asimétricos. En ese contexto cobra gran significado el simple hecho de cual es la ubicación geográfica los recursos tecnológicos y naturales con los que contamos para enfrentarnos a las transformaciones globales. También sugiere el imperativo de cambiar actitudes y hacer realidad los vínculos entre responsabilidades individuales y globales.

Esta realidad plantea para el tercer mundo un doble desafío: la búsqueda y adopción de soluciones viables ante las transformaciones, lo cual es un gigantesco reto y el segundo es el afán por superar el rezago o brecha existente en términos de respeto a los derechos económicos, sociales y culturales.

En este sentido aparece un nuevo cuestionamiento irónico: mientras la reglamentación, la consciencia, y las acciones certeras orientadas al respeto de los derechos humanos individuales, ha tenido avances mundiales, los mecanismos o fuerzas de transformación no sólo amenazan ese avance sino que incitan a convertir en una quimera el respeto a los derechos humanos económicos, sociales y culturales a escala global. Ejemplos de ello abundan.

Debemos concluir este recuento de acontecimientos en términos esperanzadores, no por demagogia o retórica sino bajo el convencimiento de que 
la humanidad es superior al resto de especies vivas de la tierra y por ello sabrá accptar la ventaja y adaptarse con plenitud a los cambios. En esta tarea es imperativo pensar las consecuencias porque no es irrelevante el costo que tenemos que pagar por entrar en la era global.

\section{Bibliogralia}

Gore, Al. La Tierra en juego. 1993.

Fislow, A. "El estado latinoamericano". Mimeo.

Hirshleifer, J. y Galazer, J. y Galazer, A. Microeconomía, Teoría y Aplicaciones. Prentice Hall, quinta edición, 1992.

Instituto Interamericano de Derechos Humanos, UNRISD, Estados de Desorden, 1995.

Kennedy, P. Hacia el siglo XXI. Plaza \& Janés, 1993.

Santory, A. "Un sólo mundo. Responsabilidades y vínculos sociales", ECA 570, abril, 1996. 